\title{
INCUBADORAS DE NEGOCIOS EN RED: CAPITAL INTELECTUAL DE INCUBADORAS DE NEGOCIOS DE LATINOAMÉRICA Y LA RELACIÓN CON SU ÉXITO ${ }^{1}$
}

\author{
Camilo Peña Ramirez ${ }^{2}$ \\ Barbara Andrea Arias Mora ${ }^{3}$ \\ Sheila Serafim da Silva ${ }^{4}$ \\ Marcelo Gonçalves do Amaral ${ }^{5}$
}

http://dx.doi.org/10.1590/1413-2311.245.90041

\section{RESUMEN}

En el presente estudio se realiza un análisis del capital intelectual de incubadoras de negocios a nivel latinoamericano, y los efectos de distintos indicadores con respecto al éxito de una incubadora de negocios (encontrarse en algún ranking), basados en un modelo de capital intelectual con la visión de incubadora en red. Para ello se trabaja con el modelo Intellectus, debido a que es considerado uno de los modelos más completos, comprensible y sencillo de aplicar, además de profundizar en los activos intangibles de las organizaciones, el cual es el objetivo del estudio. Es una investigación descriptiva y explicativa con recopilación de datos de la aplicación de cuestionarios con gerentes de 39 incubadoras de 7 países: Argentina, Bolivia, Chile, México, Paraguay, Perú y Uruguay, también se consideró respuestas de 59

\footnotetext{
${ }^{1}$ Recebido em 01/02/2019; aprovado em 31/05/2019.

${ }^{2}$ Universidad del Bio-Bio - Concepción (Chile) - http://orcid.org/0000-0002-1535-8510. E-mail: camilo.pena@usach.cl.

${ }^{3}$ Universidad del Bio-Bio - Concepción (Chile) - http://orcid.org/0000-0002-1232-7233. E-mail: baarias@egresados.ubiobio.cl.

${ }^{4}$ Universidade de São Paulo (USP) - FEA; São Paulo - SP (Brasil) - http://orcid.org/0000-0002-7104-003X. Email: sheila_serafim@yahoo.com.br.

${ }^{5}$ Universidade Federal Fluminense ((UFF) - PPGA; Volta Redonda - RJ (Brasil) - http://orcid.org/0000-00028607-3520. E-mail: marceloamaral@id.uff.br.
} 
colaboradores de las mismas incubadoras. Se adoptó un enfoque cuantitativo, utilizando pruebas estadísticas para probar las hipótesis realizadas. Finalmente las evidencias indican que número de incubados, incubados con ventas en el extranjero, total de ventas, alianzas nacionales e internacionales, alianzas públicas o privadas y rotación de empleados, influyen positivamente en éxito de una incubadora. Futuras investigaciones deberían reformular los indicadores considerados y a la vez incluir más indicadores del capital humano y del capital estructural.

Palabras claves: Capital intelectual. Incubadoras de negocios. Incubadora en red.

\begin{abstract}
This research is an analysis of the intellectual capital of business incubators in Latin America and the effects of different indicators with respect to the success of a business incubator (found in some ranking), based on a model of intellectual capital with the vision of networked incubator. For this, we work with the Intellectus model, because it is considered one of the most complete, understandable and simple to apply models, as well as delving into the organizations' intentional assets, which is the objective of the study. It is a descriptive and explanatory research with data collection from the application of questionnaires with managers of 39 incubators from 7 countries: Argentina, Bolivia, Chile, Mexico, Paraguay, Peru and Uruguay, also considered responses of 59 employees of the same incubators. A quantitative approach was adopted, using statistical tests to test the hypotheses made. Finally, the evidence indicates that the number of incubated, incubated with sales abroad, total sales, national and international alliances, public or private alliances and employee rotation, positively influence the success of an incubator. Future research should reformulate the indicators considered and at the same time include more indicators of human capital and structural capital.
\end{abstract}

Keywords: Intellectual capital. Business incubators. Networked incubators.

\title{
RESUMO
}

No presente estudo, é feita uma análise do capital intelectual de incubadoras de empresas na América Latina e os efeitos de diferentes indicadores em relação ao sucesso de uma 
incubadora de empresas (encontrada em um ranking de incubadoras), baseada em um modelo de capital intelectual com visão de incubadora em rede. Para isso, foi usado o modelo Intellectus, por ser considerado um dos modelos mais completos, compreensíveis e simples de aplicar, além de aprofundar nos ativos intangíveis das organizações, que é a proposta deste estudo. Trata-se de uma pesquisa descritiva e explicativa com levantamento de dados a partir da aplicação de questionários com gestores de 39 incubadoras de diferentes países. Foram analisadas 39 incubadoras de empresas de 7 países diferentes, sendo eles, Argentina, Bolívia, Chile, México, Paraguai, Peru e Uruguai, e também foram consideradas as respostas de 59 colaboradores das mesmas. Adotou-se uma abordagem quantitativa, usando-se de testes estatísticos para testar as hipóteses feitas. Por fim, os resultados indicam que o número de incubados, as incubados que possuem vendas no exterior, suas vendas totais, alianças nacionais e internacionais, alianças públicas ou privadas e a rotação de funcionários influenciam positivamente o sucesso de uma incubadora. Pesquisas futuras devem reformular os indicadores considerados e, ao mesmo tempo, incluir mais indicadores de capital humano e capital estrutural.

Palavras-chave: Capital intelectual. Incubadoras de empresas. Incubadoras de empresas em rede.

\section{INTRODUCCIÓN}

Las incubadoras son entidades que se dedican a apoyar a otras compañías en la etapa inicial de desarrollo o crecimiento empresarial. En la actualidad, la gran mayoría de las incubadoras de negocios les brinda los servicios básicos a los incubados (emprendedores), sin embargo, son muy pocas las que consideran el concepto de Incubadora en red, que es una estructura que propone múltiples beneficios a las organizaciones y que se basa en la gestión del capital intelectual (MORTEN et al., 2000).

El concepto de capital intelectual, nace para poder valorar los activos intangibles de una organización. Existen diversos modelos para poder identificar y valorizar los activos intangibles. Hay tres conceptos que todos los modelos consideran: capital humano, estructural y relacional (SANHUEZA, 2005). Los activos intangibles cada día están siendo más considerados por las empresas, siendo tomados como el único elemento primordial para 
competir en el mercado, adquiriendo una ventaja competitiva al identificarlos y gestionarlos correctamente.

Por esta razón se realiza esta investigación, con el objetivo de analizar el capital intelectual de acuerdo con la estructura de incubadora en red que poseen las incubadoras de negocios alrededor de América Latina. Para ello se debe constatar la literatura de diversos conceptos, incluido el modelo de gestión de capital intelectual a utilizar y el concepto de incubadora en red, para proceder a establecer un instrumento de recopilación de información, y posteriormente aplicarlo.

La hipótesis general a verificar en este estudio, es encontrar indicadores de capital intelectual que tengan relación con el éxito de una incubadora de negocios tales como: encontrarse en algún ranking. Teniendo seis hipótesis específicas de diversos indicadores del capital humano y relacional.

\section{MARCO TEÓRICO}

El marco teórico está estructurado en dos partes. Primero, será presentada la discusión acerca del capital intelectual (sus componentes, la medición y la relación con redes). En seguida, el concepto de incubadora de negocios será tratado.

\subsection{CAPITAL INTELECTUAL}

La discusión del tema empieza en los años noventa con la necesidad de valorar los activos como software y conocimiento involucrado con el desarrollo de productos y servicios. Con el tiempo, el concepto de capital intelectual se ha limitado al conjunto de activos intangibles de una empresa (STEWART, 1998). Los activos intangibles son aquellos que no tienen dimensiones físicas pero están localizados en las personas y en los procesos de las organizaciones, sistemas y en la cultura (ORTEGA; MARTINÉZ, 2013). Por tanto, el estudio de este concepto ha consistido básicamente en el análisis de los activos intangibles (GARCIA; SIMO; SALIAN, 2006). El éxito de muchas organizaciones se basa en la correcta gestión de los activos intangibles de la empresa, ya que permite concretar las estrategias de creación y llevar a cabo acciones (STEFANO; SANTORINI, 2016). El capital intelectual permite identificar y valorizar de forma más clara los activos intangibles. Por lo tanto, se ha llegado a considerar el capital intelectual como una fuente de ventaja competitiva en el mercado, aplicado en pequeñas, medianas y grandes empresas. Las organizaciones están 
analizando el valor que les generaría la gestión de este activo, provocando un potencial futuro para su empresa (RAMÍREZ et al., 2019).

\subsubsection{Componentes del capital intelectual}

El capital intelectual generalmente se descompone en tres sub dimensiones: capital humano, estructural y relacional (CALZA et al., 2014). Los cuales son definidos en relación a incubadoras de negocios: Capital Intelectual es igual al Capital Humano, más el Capital Estructural y más el Capital Relacional.

- Capital humano - Se relaciona con la actitud de las personas, en su desarrollo y aporte, logrando un desarrollo personal y profesional, al mismo tiempo que desarrolla innovación, creatividad y competencias para el surgimiento de la organización en la cual se desempeña.

- Capital estructural - Se relaciona con la infraestructura que sostiene al capital humano que lo conforman, siendo todo aquello que la organización ha desarrollado y que genera diferenciación con otras entidades.

- Capital relacional - Las empresas no son entidades aisladas, sino todo lo contrario, estas están en constante relación con organizaciones externas. Por lo tanto el capital relacional se enlaza con la red con los distintos agentes económicos que son valiosos para el desarrollo de negocios, entre los que se encuentran los proveedores, competidores y clientes.

\subsubsection{Modelos para medir el capital intelectual}

Existen variados modelos de estudios que buscan explicar, reconocer y valorar los intangibles en las organizaciones, sin embargo en cada uno de esos modelos se puede distinguir claramente la presencia de tres elementos esenciales, los cuales son: Capital humano, capital estructural y capital relacional (SANHUEZA et al., 2005).

Dentro de los modelos de capital intelectual se encuentran: Modelo Navigator de SKANDIA (EDVINSSON; MALONE, 1998), Modelo Intangible Assets Monitor (SVEIBY, 1997), Modelo Technology Broker (ANNIE BROOKING, 1996), Modelo Nova (CAMISÓN; PALÁCIOS; DEVECE, 1999), Modelo de Dirección estratégica por competencias (BUENO, 1998), Modelo Intellectus (BUENO, 2011; LONGO et al., 2011), entre otros que han desarrollado varios autores. 
El modelo Intellectus es considerado uno de los modelos más completo, comprensible y aplicable. Este modelo actualizado trae consigo diferentes categorías, de manera que se profundice los indicadores del modelo, con el objetivo de dar énfasis a los activos intangibles de una organización, en este caso incubadoras de negocio. El modelo Intellectus actualizado tiene tres elementos básicos, donde se encuentra el capital humano, como el conocimiento, capacidad para generarlo y al mismo tiempo compartir este conocimiento de manera que puedan agregar valor a la organización. El capital estructural son los conocimientos que residen en la organización, donde una vez que los empleados la abandonen, este sigue perteneciendo a la organización. Este se divide en capital organizativo y capital tecnológico, el primero se relaciona con el diseño, proceso y cultura organizativa, y el segundo con el uso de tecnologías y desarrollo de $\mathrm{I}+\mathrm{D}$. Por último, el capital relacional es el conocimiento para la organización, como para las personas que la constituyen producto del valor generado por la cantidad y calidad de relaciones que se establecen con el exterior, se divide en capital de negocio y capital social (BUENO, 2011; LONGO, et al., 2011). Otras contribuciones del modelo Intellectus pueden ser vistas en los estudios del Petty y Guthrie (2000), Bueno (2005) y Bueno, Salmador y Merino (2008).

\subsubsection{Cpital intelectual y redes}

El foco en el proceso de incubación y sus resultados se inició en la década de 1990, lo que llevó posteriormente al análisis de este proceso por medio de teoría de redes y capital intelectual (HACKETT; DILTS, 2004). Ya desde ese punto, las redes de negocios y el acceso a socios estratégicos fueron asociados al capital relacional de la incubadora en red (PENA, 2002). Esto aumentaba el crecimiento y sostenibilidad de la nueva pequeña empresa (PETERS; RICE; SUNDARARAJAN, 2004). Es así como los modelos de análisis han transitado hacia las redes, siendo la visión basada en el conocimiento incorporada en la investigación de incubadoras (RAMÍREZ, et al., 2019).

Así se identifica la necesidad de nuevas capacidades, cómo la de creación o gestión de redes, ya que, mejora la percepción del valor del servicio entregado por la incubadora (BØLLINGTOFT; ULHØI, 2005). En otros términos, el trabajo en red de los gerentes de la incubadora, y la búsqueda de nuevos conocimientos se relacionan con los resultados de los emprendimientos (HUGHES; IRELAND; MORGAN, 2007). Luego, el soporte más efectivo, ya sea en la generación de negocios o desarrollo de tecnología, es el de redes, porque esto permite transferir estos distintos tipos de conocimiento, además de otros (RAMÍREZ, et al., 
2019). El estudio de Ramírez, Moreno, Améstica y Silva (2019) analiza el capital relacional de incubadoras de negocios y los efectos con sus resultados declarados, basados en un modelo de capital intelectual.

En el caso de pequeñas empresas, algunos autores identifican a las redes entre empresas como la fuente de nuevos conocimientos, competencias (conocimientos, habilidad y actitudes) y capacidades (JORDÃO, 2015; LEMINEN et al., 2019). Según Cosh et al. (2009), pequeñas empresas que se desenvuelven en redes, pueden acceder, crear y desenvolver conocimiento para lograr ventajas competitivas. También para Martins y Sole (2010) la habilidad de entrar en redes colaborativas dinámicas, permite gestionar activamente su capital intelectual. Y para Jordão y Novas (2017), al mejorar la interacción entre los miembros de la red.

Sin embargo, los elementos de conducción del valor característicos del capital intelectual deberían ser comprendidos e identificados (JORDÃO; NOVAS, 2017). Algunos factores para pequeñas empresas, y que aplican para emprendimientos también, son los mecanismos de coordinación, el tamaño y el capital social (GARDET; MOTHE, 2012; CONNELL et al., 2014).

En definitiva, se presentan antecedentes de que el capital relacional y la capacidad de gestionar las redes de negocios, entregan beneficios en términos de innovación y del logro de los objetivos de una organización, sea esta una pequeña empresa, un emprendimiento o una incubadora. Esta interacción en red de emprendimientos e incubadoras, permitiría compartir conocimientos, así como desarrollar el capital relacional, aunque aún es difícil medir cómo.

\subsection{INCUBADORAS DE NEGOCIOS}

Las incubadoras de negocios son aceptadas como un instrumento de transferencia de tecnología entre la universidad y el sector empresarial. La Asociación Nacional de Incubación de Empresas de Estados Unidos (NBIA) define incubación de empresas como: “el proceso de apoyo a las empresas que acelera el desarrollo exitoso de empresas de nueva creación o incipientes al proporcionar a los empresarios una serie de recursos y servicios dirigidos". La incubadora es un mecanismo de desarrollo del proceso emprendedor (AMARAL, 2015) y el proceso de Incubación es un apoyo a los nuevos emprendimientos, asesorando, prestando infraestructura y servicios, con la finalidad que las empresas en formación reduzcan los riesgos, costos de puesta en marcha y proceso de aprendizaje (COYLA, 2008). 
Para llevar el proceso de incubación de las empresas es necesario organizar en etapas las actividades por las que debe pasar cada emprendimiento. Estas actividades varían en relación con el nombre y el número según el modelo utilizado. Hay un modelo presentado por la Asociación Nacional de Incubación de Empresas (NBIA) que se compone de tres etapas: Pre-Incubación, Incubación y Post-Incubación.

La corporación de Investigación Tecnológica de Chile (CITC) considera cuatro etapas en el proceso de incubación: Selección, Pre-incubación, Incubación y seguimiento, además de la etapa de Post-incubación.

El Metamodelo ${ }^{6}$ del Proceso de Incubación de Empresas, utiliza cinco etapas, que permite una descripción y modelado más detallado de cada etapa (NICHOLS; CARBALLO, 2016). Que corresponden a:

- Etapa de Promoción y selección - Incubadora presenta sus servicios y realiza convocatoria, generalmente anual o bianual. Luego se avanza a la actividad de Evaluación y selección, donde las iniciativas recibidos con evaluados y se procede a su aceptación o rechazo, en función de la factibilidad e intereses de la incubadora. Duración aproximada de 1 a 2 meses máximo.

- Etapa de Pre-Incubación - Los proyectos aceptados se incorporan y reciben servicios integrales, orientados al soporte y también capacitación para el desarrollo del plan de negocios. Duración aproximada entre 2 y 3 meses.

- Etapa de Incubación - Se ofrecen servicios integrales para desarrollar capacidades incubadas, diversas habilidades y estrategias, además de guiar el proceso de operación y desarrollo de la empresa. Este proceso se concreta con la graduación de la empresa o con su rechazo. Esta etapa dura un promedio de 12 a 18 meses.

- Etapa de Seguimiento - Se ofrecen servicios especializados para guiar la consolidación de las operaciones de la compañía, así como para apoyar el establecimiento de alianzas y contactar a los inversores. En este paso, se desarrollan actividades para monitorear el crecimiento y supervivencia de la empresa. Duración aproximada de 1 y 6 meses.

- Etapa de Post-incubación - Se ofrecen servicios de consultoría profesional enfocados en nuevos clientes y nuevos mercados $\mathrm{y}$, donde sea posible, enfocados en la internalización de la compañía. Duración aproximada entre 6 y 12 meses (NICHOLS; CARBALLO, 2016).

\footnotetext{
${ }^{6}$ Representación abstracta de los componentes de un proceso, generando un conjunto de elementos que bajo ciertos lineamientos se especializan para lograr productos más completos. (NICHOLS \& CARBALLO, 2016).
} 
Figura 1 - Etapas y macro actividades propuestas para el Metamodelo de Incubación de empresas

\section{GESTIÓN DE INFORMACIÓN CAPACTACIÓN ASESORÍA}

\begin{tabular}{|c|c|c|c|c|}
\hline $\begin{array}{c}\text { PROMIOCIONY } \\
\text { SELECCION }\end{array}$ & PRE-INCUBACIÓN & INCUBACIÓN & SEGUIMIENTO & POST-INCUBACIÓN \\
\hline$\downarrow$ & $\downarrow$ & $\downarrow$ & $\downarrow$ & $\downarrow$ \\
\hline $\begin{array}{c}\text { IDEA / PROYECTO } \\
\text { INICIAL } \\
\text { FACTIBILIDAD }\end{array}$ & $\begin{array}{c}\text { PLAN DE } \\
\text { NEGOCIOS } \\
\text { CREACION DE LA } \\
\text { EMPRESA }\end{array}$ & $\begin{array}{c}\text { ARRANQUE DE } \\
\text { OPERACIONES }\end{array}$ & $\begin{array}{c}\text { CRECIMIENTO } \\
\text { Y } \\
\text { CONSOLIDACIÓN }\end{array}$ & $\begin{array}{c}\text { RED DE CONTACTOS } \\
\text { INTER- }\end{array}$ \\
$\begin{array}{c}\text { NACIONALALAOLN } \\
\text { Y GLOBALIZACIÓN }\end{array}$ \\
\hline
\end{tabular}

Fuente: Nichols y Carballo (2016, p. 114).

\subsubsection{Tipos de incubadoras de negocios}

Es relevante a la hora de poner en marcha una idea, conocer los tipos de incubadoras de negocios existentes para saber cuál es la que mejor se adaptara a las necesidades del negocio (COTERA et al., 2016). Sin embargo, clasificar los tipos de incubadoras no es simple, ya que no existen dos tipos de incubadoras exactamente iguales. Si bien el objetivo general de las incubadoras es desarrollar empresas, cada una de las incubadoras de negocios tiene diferentes prioridades. Incluso entre incubadoras de modelos similares, existen diferencias entre sus operaciones y objetivos (Bøllingtoft; Ulhøi, 2005).

También el sector de las incubadoras de empresas es muy novedoso, por lo que se encuentra en constante cambio. Sin embargo, según el Instituto Mexiquense del Emprendedor (IME) (Emprendedor ) y el Centro de Emprendedores de la Fundación DPT en Argentina (DPT), coinciden en una clasificación actual de tres tipos de incubadoras.

- Incubadoras tradicionales - Apoya la creación de empresas en sectores tradicionales que requieren infraestructura física y tecnológica, así como sus mecanismos operativos básicos, como papelería, ropa, textiles, estética, restaurantes, lavanderías, joyas, etc. El tiempo de incubación suele ser entre los tres y seis meses.

- Incubadoras de tecnología intermedia - Apoya la creación y el crecimiento de empresas que requieren infraestructura física, tecnológica y mecanismos operativos semiespecializados e involucran elementos de innovación. Algunos ejemplos son: Desarrollo 
simple de redes, servicios basados en tecnologías de información y diseño, aplicaciones web, nuevas máquinas y herramientas para la industria, telecomunicaciones, etc. El periodo de incubación ronda alrededor de los 12 meses.

- Incubadoras de alta tecnología - Este tipo de incubadora debe apoyar el desarrollo de empresas en sectores más avanzados, como las tecnologías de la información y la comunicación (TIC), la biotecnología, la industria farmacéutica, los sistemas microelectromecánicos (MEM`S), entre otros. El período de incubación de estas empresas puede alcanzar los dos años.

Hay también una clasificación por las generaciones de incubadoras donde en la primera generación el foco es compartir espacios y recursos. En una segunda generación el foco son los servicios de suporte al desarrollo de negocios. Por fin, la tercera generación, la creación de redes es el aspecto principal (ANPROTEC, 2016).

Otro instrumento de soporte a los emprendedores son las aceleradoras de negocios, que según el reporte de mejores prácticas de las aceleradoras de negocios en el año 2015 efectuado por Unitus Seed Fund (ACHARYA, 2015), señala las siguientes aceleradoras existentes:

- Academias Aceleradoras (Startup Academies) - Este tipo de aceleradores están destinados a encargarse de nuevas empresas en la etapa prematura, en el proceso de desarrollo de la idea.

- Aceleradores generales - Estos aceleradores ofrecen servicios de apoyo a empresarios, como servicios de oficina, asistencia comercial, etc.

- Hiperaceleradoras (Hyper - accelerators) - Estas aceleradoras se dirigen a empresas más establecidas, proporcionándoles mentorías más enfocadas, acceso a inversionistas y un programa más riguroso de entrenamiento (MODESTO, 2018).

Las aceleradoras de negocios en general son más adecuadas para empresas que tengan cierta interacción con el mercado, y que necesiten un acceso al conocimiento y al capital relacional bien definido (MODESTO, 2018).

\subsection{2 ¿Qué son las incubadoras en red?}

Del mismo modo que los emprendedores y sus emprendimientos, las incubadoras también son organizaciones y, como tales, atraviesan distintos procesos de desarrollo que, en una gran cantidad de casos, sufre momentos determinantes (KANTIS, 2017). 
La red y el apoyo de las incubadoras para el espíritu empresarial surgieron durante los años 1990 a través de la aparición del diseño dominante "Incubadora en red". El concepto de incubadora en red (Networked Incubator, en inglés) fue establecido alrededor del año 2000 (HANSEN et al., 2000). Trabajo en red es fundamental para incubadoras de empresas, ya que les ayuda a proporcionar servicios de valor añadido a los incubados (CALZA et al., 2014).

En la antigüedad, el énfasis de las incubadoras de negocios se ha centrado básicamente en la prestación de los servicios centrales del negocio y el diseño de la misma, pero los enfoques más recientes buscan la prestación de una red rica, mediante la cual una incubadora puede participar en colaboraciones (HUGHES; IRELAND; MORGAN, 2007).

La incubación mejora cuando una empresa inicial se encuentra en una incubadora en red, debido que la incubación se define como el proceso que permite a las nuevas empresas lograr crear valor competitivo en el mercado mediante la incorporación en un sistema de red, el cual les proporciona acceso a una amplia red con conexiones imprescindibles para su negocio (HUGHES; IRELAND; MORGAN, 2007). Las relaciones iniciales que tenga una incubadora, así como también su rol de intermediación son cruciales para el apoyo a emprendedores. Existen dos tipos de interacciones, las sociales y las de negocios, que en conjunto conforman el ecosistema emprendedor (APA; GRANDINETTI; SEDITA, 2017). Así, el capital relacional que disponga la incubadora, es clave en la función de soporte a los emprendimientos.

El crecimiento de las habilidades emprendedoras por las empresas incubadas es soportado por el capital social generado de las relaciones entre los incubados, en base a la confianza e identificación mutua, y porque comparten un lenguaje y perspectiva común (ASCIGIL; MAGNER, 2009).

Los principales objetivos de la creación de redes son el acceso a los recursos y adquisición de conocimiento. A medida que una incubadora se enfoca en estos objetivos, va desarrollando relaciones interactivas, determinando su grado de capital social y regulando el grado probable y la naturaleza del valor creado posteriormente (HUGHES; IRELAND; MORGAN, 2007).

Los servicios prestados por una incubadora, en general, le dan mayor credibilidad al negocio, además de ser muy relevantes para el desarrollo de redes de negocios para el emprendimiento. Aquellos emprendedores que recibieron apoyo en la creación de sus redes de negocios están más satisfechos de los servicios de una incubadora. La pregunta es, cuales incubadoras tienen las capacidades para proveer este servicio (TOTTERMAN; STEN, 2005). 


\section{METODOLOGÍA DE INVESTIGACIÓN}

Este trabajo es una investigación descriptiva y explicativa basada en una pesquisa cuantitativa (survey). El foco ha sido países de Latinoamérica, con excepción de Brasil, que comparten características y ambientes de negocios.

\subsection{INCUBADORAS DE AMÉRICA LATINA}

Actualmente no existe ningún listado de incubadoras a nivel Latinoamericano, por esta razón se genera un estimado de la población con respecto a los informes "The UBI Global" y "Informe Acelerador de LATAM 2016", y la asistencia al "III encuentro de incubadoras de negocio de América Latina y el Caribe".

- "Informe Acelerador de LATAM 2016", contacto a 157 instituciones de 11 países a lo largo de América Latina, obteniendo 98 respuestas.

- “The UBI Global”, considero 6 regiones, 53 países, 259 programas. Correspondiendo a América Latina el 39\%, por lo tanto 101 incubadoras de negocios.

- “III Encuentro de Incubadoras de Negocios de América Latina y el Caribe", asisten más de 20 incubadoras del ecosistema de diversos países extranjeros.

Por tanto, un estimado de la cantidad de incubadoras que existen en América Latina (Argentina, Bolivia, Chile, México, Paraguay, Perú y Uruguay) es alrededor de 100 incubadoras de negocios. Solo en Brasil, ANPROTEC estima que sean acerca de 350 incubadoras y aceleradoras. Por esto, se ha decidido no incluir a Brasil para no afectar el muestreo.

\subsection{OBTENCIÓN DE DATOS Y VARIABLES}

La obtención y recopilación de datos es a través de cuestionarios mediante dos métodos, el primero en papel de forma presencial en el "III Encuentro de Incubadoras de Negocios de América Latina y el Caribe" y el segundo mediante la encuesta online enviada a los asistentes del encuentro por medio de contacto realizado, a través de correo electrónico y red de linkedin. Estos cuestionarios fueron formulados en base a los indicadores planteados para el modelo de capital elegido. 
Se formularon dos cuestionarios para la obtención de datos de la incubadora, un cuestionario es carácter único dirigido al líder, director o ejecutivo a cargo de la incubadora, buscando obtener los datos macros y de carácter global de la incubadora, haciendo énfasis en diversos puntos relevantes. El segundo está dirigido a todos los colaboradores de la incubadora, este busca obtener los datos sobre la relación entre los trabajadores y la institución.

Se analizaron 39 incubadoras de negocios de siete países diversos, donde se encuentran: Argentina, Bolivia, Chile, México, Paraguay, Perú y Uruguay. También se consideró respuestas de 59 colaboradores.

Variables considerados para el estudio:

- Clientes relevantes - Antecedentes históricos del comportamiento de los incubados por la entidad, en temas de cantidad de incubados y sus avances en el mercado, tanto a nivel nacional como internacional, ventas y la perduración en el tiempo.

- Relación con clientes - Relaciones con el cliente o segmentos de clientes potenciales de los bienes o servicios de la incubadora. Tipo y grado de comunicación e interacción tanto con la incubadora, como con otros incubados.

- Relaciones con aliados - Acuerdos de colaboración más duraderos con otras instituciones, por ejemplo, con entidades gubernamentales o con empresas predominantes en el sector.

- Relaciones con empleados - Relaciones con los miembros de la plantilla de la organización, en su consideración de clientes internos, conducentes a desarrollar las actitudes y capacidades recogidas como elementos y variables del capital humano.

- Relaciones con las administraciones públicas - Interacción con la administración pública para promover los intereses generales de la sociedad.

- Aptitudes (Saber) - Referente al conocimiento que la persona tiene sobre las cosas, que le permite desempeñarse adecuadamente en sus funciones dentro de un empleo.

\subsection{MODELO}

En la Figura 2 se muestra el modelo utilizado en la investigación, considerando: Hipótesis General: éxito incubadora de negocios (Reconocida en ranking de medición). Hipótesis Específicas:

- $\mathrm{H}_{1}$ : Existe una relación entre algún indicador de (Clientes relevantes) y haber sido reconocida en un ranking. 
- $\mathrm{H}_{2}$ : Existe una relación entre algún indicador de (Relación con clientes) y haber sido reconocida en un ranking.

- $\mathrm{H}_{3}$ : Existe una relación entre algún indicador de (Relación con aliados) y haber sido reconocida en un ranking.

- $\mathrm{H}_{4}$ : Existe una relación entre el indicador de (Relación con la administración pública) y haber sido reconocida en un ranking.

- $\mathrm{H}_{5}$ : Existe una relación entre algún indicador de (Relación con trabajadores) y haber sido reconocida en un ranking.

- $\mathrm{H}_{6}$ : Existe una relación entre el indicador de Aptitudes (Saber) y haber sido reconocida en un ranking.

Figura 2 - Modelo propuesto

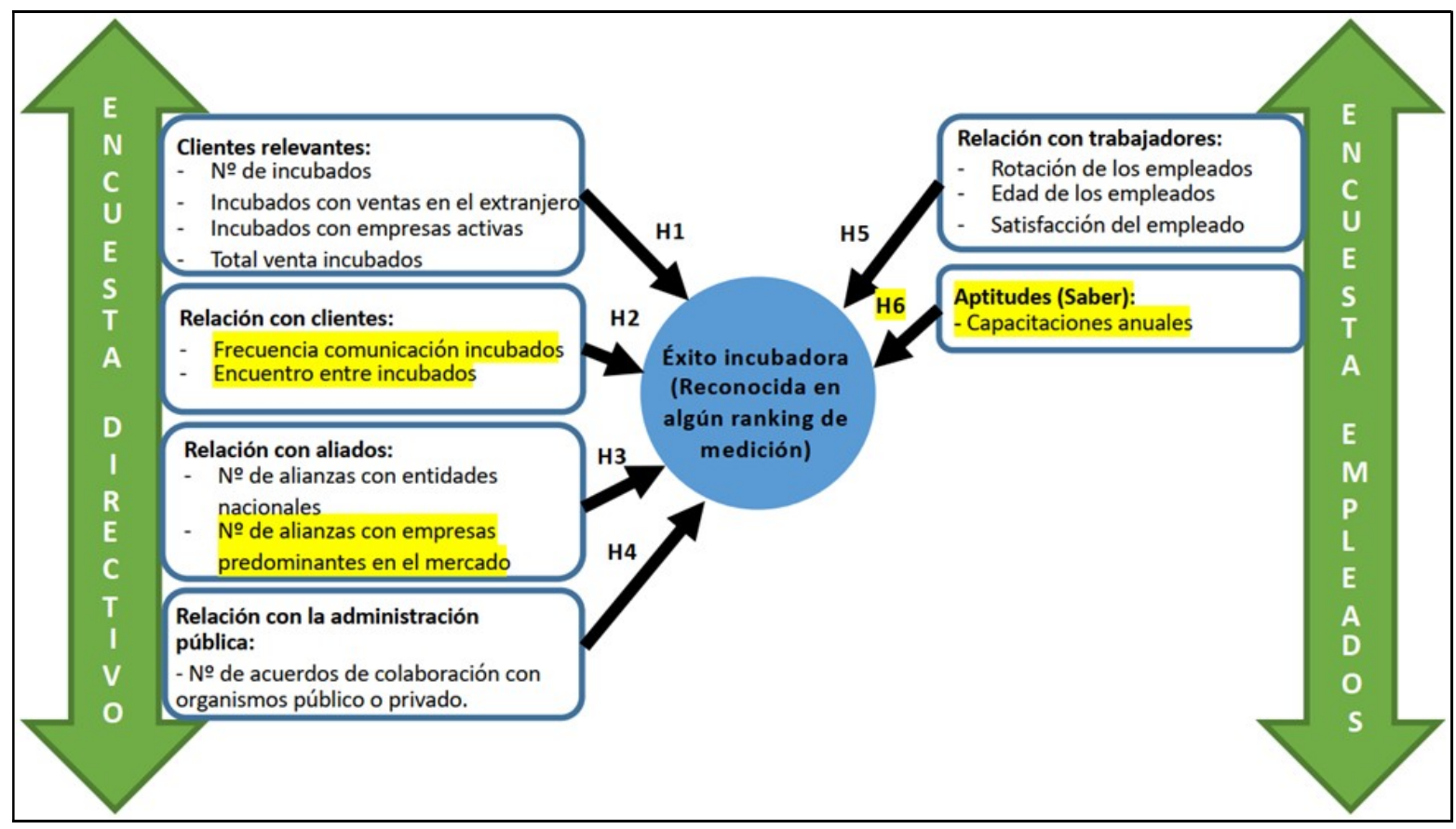

Fuente: elaborado por los autores.

\section{RESULTADOS}

Primero, se presentaron los resultados del análisis descriptivo (Tabla 1), luego se presentaron los resultados del análisis estadístico, y luego se analizaron los resultados.

El tiempo de funcionamiento de las incubadoras latinoamericanas se distribuye principalmente con un $46 \%$ equivalente a 18 incubadoras en un tiempo entre 0 a 5 años. El 
resto de las incubadoras se distribuye en forma similar existiendo una cantidad de incubadoras en los demás rangos de tiempo de funcionamiento. Esto demuestra que a nivel latinoamericano hay una cantidad mayoritaria de incubadoras de reciente creación y que para el resto existe una diversidad de tiempos de servicios por parte de las incubadoras.

El 44\% de las incubadoras cuentan con una plantilla baja de trabajadores entre 0 a 5 , esto quiere decir que la estas incubadoras no entregan una gran cantidad de empleos. Sin embargo, lo sigue con un $31 \%$ incubadoras que entregan 16 o más empleos. Por lo tanto, la mayoría considera una plantilla escasa correspondiendo a incubadoras pequeñas, sin embargo, la segunda gran mayoría corresponde a incubadoras de gran tamaño.

Las incubadoras que participaron en el estudio, corresponden mayoritariamente a incubadoras que se encuentran en rankings de medición con un 59\% correspondiente a 23 incubadoras. Donde se consideran 10 que han sido contempladas en rankings globales como es UBI Global y 13 a rankings nacionales. El otro 41\% no se encuentra en ningún ranking de medición, correspondiendo a 16 incubadoras, que en su mayoría llevan poco tiempo de funcionamiento y/o cuenta con una escasa plantilla de colaboradores.

El número de incubados se encuentra principalmente entre los 0 a 19 incubados correspondiente al año 2017. Esto se puede deber a que la gran mayoría es de reciente creación y cuenta con una dotación de personal escasa, por lo tanto no se cuenta con tanto recursos humanos para guiar los procesos de incubación, además existen algunas entidades que cumplen el rol dual de incubación y aceleración, por lo que destinan parte de su plantilla de empleados a otras iniciativas de aceleración.

Las incubadoras de negocios consideradas en el estudio se financian principalmente de fondos mixtos con un $56 \%$ que corresponde a 22 incubadoras. Seguido de un $28 \%$ que corresponde a financiamiento público, principalmente por incubadoras de universidad o municipales. Fondos propios son utilizados por 5 incubadoras que corresponden al 13\% del total de incubadoras consideradas. Finalmente solo una incubadora se financia mediante fondos privados, correspondiente a una incubadora mexicana.

Las iniciativas de emprendimiento que desarrollan las incubadoras latinoamericanas tienen un enfoque principalmente nacional con un 33\%, porcentaje que es seguido por un $28 \%$ que se desarrolla a nivel regional, el $21 \%$ por incubadoras que se extienden a nivel internacional, esto indica que hay incubadoras que están escalando a un territorio más global, lo que es permitido por las redes de aliados que contemplan. En menor medida existen incubadoras que levantan proyectos más provinciales y locales. 
Tabla 1: Antecedentes generales incubadoras de América Latina

\begin{tabular}{|c|c|c|c|}
\hline & & $\mathbf{N}$ & $\%$ \\
\hline & 0 - 5 años & 18 & $46.15 \%$ \\
\hline Tiempo de & 6 -10 años & 9 & $23.08 \%$ \\
\hline \multirow[t]{3}{*}{ Funcionamiento } & $11-15$ años & 6 & $15.38 \%$ \\
\hline & 16 o más años & 6 & $15.38 \%$ \\
\hline & 0 -5 empleados & 17 & $43.59 \%$ \\
\hline \multirow{3}{*}{ Número de Empleados } & 6 - 10 empleados & 6 & $15.38 \%$ \\
\hline & 11-15 empleados & 4 & $10.26 \%$ \\
\hline & 16 o más empleados & 12 & $30.77 \%$ \\
\hline \multirow{3}{*}{$\begin{array}{l}\text { Reconocido en algún } \\
\text { ranking de medición }\end{array}$} & $\mathrm{Si}$ & 23 & $58.97 \%$ \\
\hline & No & 16 & $41.03 \%$ \\
\hline & $0-19$ & 20 & $51.28 \%$ \\
\hline \multirow{4}{*}{$\begin{array}{l}\text { Número de incubados } \\
\text { del año anterior }\end{array}$} & $20-49$ & 8 & $20.51 \%$ \\
\hline & $50-99$ & 7 & $17.95 \%$ \\
\hline & Más de 100 & 4 & $10.26 \%$ \\
\hline & Fondos mixtos & 22 & $56.41 \%$ \\
\hline \multirow{4}{*}{$\begin{array}{c}\text { Financiamiento } \\
\text { Incubadoras }\end{array}$} & Fondos privados & 1 & $2.56 \%$ \\
\hline & Fondos propios & 5 & $12.82 \%$ \\
\hline & Fondos públicos & 11 & $28.21 \%$ \\
\hline & Internacional & 8 & $20.51 \%$ \\
\hline \multirow{4}{*}{$\begin{array}{c}\text { La iniciativas tienen un } \\
\text { alcance }\end{array}$} & Nacional & 13 & $33.33 \%$ \\
\hline & Regional & 11 & $28.21 \%$ \\
\hline & Provincial & 2 & $5.13 \%$ \\
\hline & Local & 5 & $12.82 \%$ \\
\hline
\end{tabular}

Fuente: elaborada por los autores.

A partir de aquí se presentarán los resultados en función del modelo (Figura 2) y las variables analizadas: base de clientes relevantes, relación con los clientes, base de aliados, relaciones con la administración pública, relaciones con los trabajadores, aptitudes (saber).

- Base clientes relevantes - La cantidad de incubados promedio, por cada incubadora es de 35 , lo que refleja un mayor interés en el emprendimiento y las buenas prácticas de 
las incubadoras. Un $26 \%$ de los incubados poseen ventas en el extranjero, y la cantidad de incubados con empresas activas es de un 33\%, ambas cantidades no son consideradas bajas, sin embargo, el propósito de las incubadoras de negocios es que los emprendimientos compitan y se mantengan en el mercado después de finalizado su proceso de incubación. Los clientes relevantes de las incubadoras son aquellos que necesitan apoyo para para iniciar, al contar con una diversidad de entidades en el conjunto estudiado, las incubadoras pueden ser desde profesionales universitarios o cualquier persona ajena con un vínculo en las respectivas incubadoras de negocios.

- Relación con los clientes - Los procesos a través de cómo se relacionan con los incubados son fluidas, realizando actividades entre los incubados en promedio de siete veces durante su proceso de incubación, con la posibilidad de interactuar entre ellos, con la finalidad de la colaboración para el logro de objetivos y solucionar problemáticas en común. También existe una comunicación con los incubados en promedio de dos veces por semana, con el objetivo de no perder la comunicación y ritmo de trabajo para el desarrollo de sus emprendimientos.

- Base de aliados - Presenta alianzas con la base de clientes, en promedio cuatro alianzas con entidades nacionales e internacionales, y 5 con empresas predominantes en el mercado, no es considerada baja la cantidad de alianzas, sin embargo, aún falta mucho por construir en estos temas, debido que la estructura de incubadoras en red es fundamental las alianzas establecidas con las entidades del entorno, también para emprendimiento escalables es fundamental las alianzas a nivel internacional.

- Relaciones con la administración pública - Existe relación con organismos públicos y privados ya que algunas de las incubadoras a nivel latinoamericano se financian mediantes estas entidades, ya sean públicas o privadas, por lo tanto mantienen una relación estrecha y con un mutuo beneficio. El resto es financiado mediante otros fondos, también realizan colaboración con estas entidades para el logro de sus objetivos y crecimiento tanto de sus incubados como de las incubadoras de negocios. Presentan en promedio cuatro acuerdos de colaboración con organismos públicos o privados, lo que no es considerado bajo, sin embargo, para construir una correcta estructura en red, es fundamental la colaboración con las entidades del entorno.

- Relaciones con los trabajadores - Los trabajadores se sienten satisfechos con el trabajo en el cual se desempeñan, con un índice de satisfacción del 74\%. La cantidad de empleados con contrato indefinido es baja con un $32,2 \%$, la gran mayoría cuenta con contrato anual u honorarios, con una tasa de rotación interna del 52,54\%, que en su 
gran mayoría es con ascenso dentro de la entidad. Existe una alta factibilidad de levantar proyectos de forma interna para los trabajadores con un 88,14\%. La edad media de los empleados que componen las incubadoras es de 32 años, y la media en que los trabajadores permanecen en la organización es de 4,6 años, con una media de 2,7 años en cada cargo.

- Aptitudes (Saber) - Las incubadoras consideradas en esta investigación tienen un promedio de 3 capacitaciones durante el año. Lo cual es un número muy favorable, ya que se requiere un continuo aprendizaje por parte del personal que compone las incubadoras de negocios, con la finalidad de poder entregar mejores servicios y, con ello más y mejores herramientas para forjar sus emprendimientos.

El análisis estadístico tiene la finalidad de comprobar las hipótesis formuladas, y para esto se realizó mediante la prueba Chi-cuadrado. La prueba de Chi-cuadrado es una prueba de hipótesis no paramétrica que busca evaluar la existencia de una diferencia entre variables cualitativas. Debido a sus características no paramétricas, no depende de los parámetros de población como la media y la varianza, por ejemplo. Se eligió la prueba de Chi-cuadrado porque puede comparar las posibles divergencias entre las frecuencias observadas y esperadas para cada una de las seis hipótesis analizadas. Dado que las frecuencias son muy cercanas a cero (0), se puede decir que las proporciones se comportan de manera similar. Cabe mencionar que se respetaron los siguientes requisitos para elegir la prueba de Chicuadrado: los grupos fueron independientes, los elementos de cada grupo se seleccionaron al azar, las observaciones fueron frecuencias o conteos, cada observación pertenece a una sola categoría y la muestra debe ser relativamente grande. Se obtuvieron los siguientes resultados:

Base de clientes relevantes $\left(\mathrm{H}_{1}\right)$ : Sólo, número de incubados, incubados con ventas en el extranjero y total de venta de incubados influyen positivamente en el éxito de una incubadora, es decir, reconocida en un ranking ( $\mathrm{P}$-valor $<0,05)$. $\underline{\text { Relación con los clientes }}$ $\left(\mathrm{H}_{2}\right)$ : No existen indicadores influyentes con el éxito de una incubadora (p-valor $\left.<0,05\right)$. Relación con aliados $\left(\mathrm{H}_{3}\right)$ : Sólo el número de alianzas con entidades nacionales e internacionales influyen positivamente en el éxito de una incubadora (P-valor $<0,05)$. Relación con la administración pública $\left(\mathrm{H}_{4}\right)$ : Solo el número de acuerdos de colaboración con organizaciones públicas o privadas tiene una influencia positiva en el éxito de una incubadora (P-valor $<0,05)$. Relaciones con los trabajadores $\left(\mathrm{H}_{5}\right)$ : Sólo la rotación de los trabajadores influye positivamente en el éxito de una incubadora (P-valor $<0,05)$. Aptitudes (Saber) $\left(\mathrm{H}_{6}\right)$ : No existen indicadores influyentes con el éxito de una incubadora ( $p$-valor $<0,05$ ). 


\section{DISCUSIÓN Y CONSIDERACIONES FINALES}

Se consideró el modelo "Intellectus" (2011, actualizado) al ya haber sido utilizado en el estudio de incubadoras en Chile (RAMÍREZ et al., 2019), y considerarse un modelo gestión de capital intelectual completo, comprensible y fácil de aplicar. Además de considerar los recursos intangibles y variables relacionadas con el progreso de las incubadoras de negocios, que es la finalidad del estudio.

Las variables consideradas en el estudio, con respecto al capital relacional son la base de clientes relevantes, los procesos de relación con los clientes, las relaciones con la administración pública, la base de aliados y la relación con los trabajadores, con respecto al capital humano se consideran aptitudes (saber).

Los antecedentes generales que presentan las incubadoras de negocios de América Latina participantes son: el $46,15 \%$ tiene un tiempo de funcionamiento de 0 a 5 años, el $43,59 \%$ cuenta con una plantilla de empleados de 0 a 5 , sin embargo la cantidad que lo sigue con un $30,77 \%$ cuenta con una plantilla del mayor rango, de 16 o más empleados, el 58, 97\% ha sido reconocido en ranking de medición, el 51,28\% presenta una cantidad de incubados de 0 a 19 durante el año, el 56,41\% se financia mediante fondos mixtos y el 33,3\% tiene un alcance nacional.

La base de clientes relevantes de las incubadoras tiene en promedio al año, 35 incubados, lo que refleja un mayor interés por el emprendimiento y las buenas prácticas de las incubadoras, sin embargo este promedio está por debajo por el presentado en las incubadoras nacionales que corresponde a 45 incubados. Sin embargo con respecto al porcentaje de incubados con ventas en el extranjero las incubadoras latinoamericanas están por sobre las nacionales, con un $26 \%$ y un $17 \%$ respectivamente y con respecto al índice de empresas activas tienen resultados similares alrededor del $30 \% \%$.

Se presenta relaciones con la base de aliados, sin embargo al estar midiendo la estructura de incubadora en red, se hace fundamental el aumento de las alianzas con las entidades que se encuentran en el entorno, y al momento de que se requiera la escabilidad de los emprendimientos a nivel global es fundamental las alianzas internacionales. Con respecto a los resultados a nivel nacional, existen semejanzas en alianzas nacionales e internacionales, obteniendo a nivel nacional en promedio 3 y a nivel latinoamericano 4, resultando una pequeña distancia. 
De igual manera se presentan relaciones con la administración pública, debido a la existencia de entidades que son financiadas por estas y otras que crean alianzas para la colaboración mutua, que de igual forma al momento de querer construir una estructura en red es fundamental el aumento de alianzas con entidades públicas y privadas del entorno. El promedio se encuentra por debajo de los resultados a nivel nacional, presentando en promedio de acuerdos con organismos público o privado 4 y 8 respectivamente.

Finalmente, se realiza un análisis estadístico mediante la prueba Chi-cuadrado para las seis hipótesis y cada uno de sus indicadores para comprobar si existe una relación positiva en el éxito de una incubadora, es decir, si es reconocida en un ranking ( $p$-valor $<0,05$ ).

Donde se obtiene los indicadores que influyen positivamente en el éxito de una incubadora de negocios son: Base de clientes relevantes (H1) los indicadores número de incubados, incubados con ventas en el extranjero y total de venta incubados; Relación con Aliados (H3) el indicadores alianzas con entidades nacionales e internacionales; Relación con la administración pública (H4) el indicador Número de acuerdos de colaboración con organismos público y privado; Relación con los trabajadores (H5) el indicador Rotación de los empleados. Por otro lado las hipótesis: Relación con clientes (H2) y Aptitudes (H6), no son influyentes para el éxito de una incubadora de negocios. Por lo tanto, contrario a lo que se esperaba ninguno de los indicadores añadidos, ni de la hipótesis (H6) influye en el éxito de una incubadora de negocios, sin embargo existen cuatro hipótesis que si son influyentes. Así, mediante la prueba estadística Chi-cuadrado ( $p$-valor $<0,05$ ), se comprueba que existe relación de seis indicadores pertenecientes a cuatro hipótesis específicas, que tienen relación con el éxito de las incubadoras de negocios.

El éxito de muchas organizaciones se basa en la correcta gestión de los activos intangibles de la empresa, ya que permite concretar las estrategias de creación y llevar a cabo acciones (STEFANO et al., 2016). La estructura de incubadora en red está diseñada para poner en marcha un mayor número de empresas con mayor rapidez (MORTEN et al., 2000). Si bien los ejecutivos se encuentran conscientes de la importancia de las redes, desconocen los niveles de desarrollo que deben lograr para lograr llegar a crecer hasta el punto de llegar a un mercado externo, es decir, redes locales y redes globales. (PEÑA, 2012).

Existe una gran cantidad de incubadoras de negocios de América Latina que tienen una duración prematura y que no cuentan con una cantidad de plantilla de empleados grande, lo que provoca que no se realicen mayores incubaciones por año. Sin embargo, en aspectos de incubados con ventas en el extranjero y la cantidad de empresas activas presentan buenos resultados, lo que es fundamental ya que su propósito es que los emprendimientos logren 
competir y permanecer en el mercado una vez finalizado su proceso de incubación, y para incubadoras con proyección internacional, que los emprendimientos sean escalables internacionalmente. Por lo otro lado, con respecto a la relación con los incubados, están generando una comunicación frecuente con ellos, además de crear las instancias para que puedan compartir con otros incubados con la finalidad de realizar colaboración entre ellos.

De igual manera las alianzas con entidades del entorno de la base de aliados y administración pública, existen, pero se espera que aumenten con la finalidad de lograr una red diversificada, para el aumento de la colaboración. Para concluir con respecto a la relación colaboradores esta es óptima y se sienten satisfechos por sus labores dentro de la organización, además de brindarles a su capital humano capacitaciones de modo que se vayan perfeccionando para entregar mejores servicios a sus incubados.

Las limitantes que influyen en este estudio fueron principalmente la disponibilidad de los encargados/gerentes y colaboradores pertenecientes a las incubadoras, ya que la participación era de carácter voluntaria responder un cuestionario sin una retribución, sólo el mero hecho de compartir los resultados de este estudio. Para conseguir respuesta de los cuestionarios se extendía el periodo de tiempo, lo cual es una limitante muy importante, y hubo que realizar cambios en cómo llegar al receptor, debido a que el correo electrónico no se obtenían respuestas, y debido a que se trataba de llamadas telefónicas internacionales que no eran sencillas de conseguir, se tuvo que utilizar otras herramientas digitales.

Además, es posible presentar algunas limitantes de la metodología, como ejemplo, la elección exclusiva del método cuantitativo mediante el cual no fue posible profundizar en el significado de las respuestas. Sería interesante complementar este estudio con el método cualitativo para explorar las respuestas de los administradores de la incubadora.

Para futuras líneas de investigación sería recomendable reformular los indicadores considerados, en especial para las hipótesis (H2) y (H6).

\section{REFERENCIAS}

ACHARYA, N. The results of the first ever study of accelerator best practices. Forbes, 2015. Disponível em: https://www.forbes.com/sites/nishacharya/2015/10/21/the-results-ofthe-first-ever-study-of-accelerator-best-practices/\#431801ad6d35. Acesso em: 15 Nov. 2018. AMARAL, M. Management and assessment of innovation environments. Triple Helix, v. 2, n. 1, p. 1-20, 2015. 
ANPROTEC - Associação Nacional de Entidades Promotoras de Empreendimentos Inovadores. Estudo de Impacto Econômico: Segmento Incubadoras de Empresas do Brasil. Brasilia, 2016.

ANTUNES, M. T. Controladoria e o Capital Intelectual: um estudo empírico sobre sua gestão. Revista de Contabilidade e Finanças, n. 41, p. 21-37, 2006.

APA, R.; GRANDINETTI, R.; SEDITA, S. The social and business dimensions of a networked business incubator: the case of H-Farm. Journal of Small Business and Enterprise Development, n. 24, v. 2, p. 198-221, 2017.

ASCIGIL, S.; MAGNER, N. Business incubators: leveraging skill utilization through social capital. Journal of Small Business Strategy, v. 20, n. 1, p. 265-290, 2009.

BØLLINGTOFT, A.; ULHØI, J. The networked business incubator-leveraging entrepreneurial agency? Journal of Business Venturing, v. 20, n. 2 p. 265-290, 2005.

BUENO, Eduardo et al. Modelo Intellectus de medición, gestión e información del capital intelectual (Nueva versión actualizada). IADE, Universidad Autónoma de Madrid, Madrid, 2011.

CALZA, F.; DEZI, L.; SCHIAVONE, F.; SIMONI, M. The intellectual capital of business incubators. Journal of Intellectual Capital, v. 15, n. 4, p. 597-610, 2014.

COTERA, E.; RUIZ, A.; ZAVALA, M.; DELGADILLO, P. Las incubadoras de negocios: un modelo económico que ayuda $\mathrm{y}$ orienta proyectos empresariales. Revista Iberoamericana de Producción Académica y Gestión Educativa, v. 4, 2016.

COYLA, M. Capital intelectua, gestión del conocimiento e innovación mediante la incubadora de empresas en universidades. Revista de investigación, v. 4, n. 2, 2008.

EMPRENDEDOR, I. (n.d.). Funcionamiento de una incubadra de empresas. Secretaría de Desarrollo Económico. Disponivel em:

http://portal2.edomex.gob.mx/ime/emprendedores/incubadoradeempresas/comofu ncionaunaincubadora/index.htm. Acesso em: 13 mar. 2019.

FUNDACIÓN DPT. (n.d.). Retrieved from http://www.fundaciondpt.com.ar/site/index.php/propuesta-empresaria/centro-deemprendedorismo/317-tipos-de-incubadoras-de-negocios. Acesso em:

GARCIA, M.; SIMO, P.; SALIAN, J. M. La evolución del capital intelectual y las nuevas corrientes. Intangible Capital, v. 2, n. 3, p. 277-307, 2006.

HUGHES, M.; IRELAND, R. D.; MORGAN, R. E. Simulating dynamic value: Social capital and business incubation as a pathway to competitive success. Long Range Planning, v. 40, n. 2, p. 154-177, 2007. 
KANTIS, H. Evaluación de incubadoras de empredimientos: el caso Uruguayo y su comparación con el benchmark. Banco Interamericano de Desarrollo, Documento para discusión Nº IDB-DP-530, Chile, Nov., 2017.

MODESTO G., Y. Evaluación del modelo de las aceleradoras de empresas y su presencia en el ecosistema latinoamericano de emprendimientos tecnológicos. Revista Tekhné, de la Facultad de Ingeniería., v. 21, n. 4, p. 50-67, 2018.

HANSEN, M., CHESBROUGH, H., NOHRIA, N., SULL, D. Networked incubators. Harvard business review, v. 78, n. 5, p. 74-84, 2000.

NICHOLS , A.; CARBALLO, Y. Metamodelo del Proceso de Incubación de Empresas: Componente Modelo de Negocio. IV Simposio Científico y Tecnológico en Computación, 2016 .

NICHOLS, A.; CARBALlO, Y. Metamodelo del Proceso de Incubación de Empresas: Componente Especificación de Etapas, Requisitos según Modelo FURPS + y Criterios del Producto. Memorias de la Cuarta Conferencia Nacional de Computación, Informática y Sistemas, 2016.

PEÑA , C. Gestión de redes en emprendimientos internacionales: ¿Cuál es el parceiro de servicios globales? ENEFA Proceedings, v. 5, 2012.

SANHUEZA, R. Los activos intangibles: Presentación de algunos modelos desarrollados. Horizontes empresariales, V. 4, p. 47-60, 2005.

STEFANO, N. M.; SANTORI, S. The knowledge management and intellectual capital: theoretical approach to discussion. Ingeniería Industrial, n. 2, p. 179-192, 2016.

TÖTTERMAN, H.; STEN, J. Start-ups: Business incubation and social capital. International small business journal, v. 23, n. 5, p. 487-511, 2005. 